University of Nebraska - Lincoln

DigitalCommons@University of Nebraska - Lincoln

Michigan Bovine Tuberculosis Bibliography and

Database

Wildlife Disease and Zoonotics

2002

\title{
Environmental and Farm Management Factors Associated with Tuberculosis on Cattle Farms in Northeastern Michigan
}

John B. Kaneene

Colleen S. Bruning-Fann

Larry M. Granger

RoseAnn Miller

Barbara A. Porter-Spalding

Follow this and additional works at: https://digitalcommons.unl.edu/michbovinetb

Part of the Veterinary Medicine Commons

Kaneene, John B.; Bruning-Fann, Colleen S.; Granger, Larry M.; Miller, RoseAnn; and Porter-Spalding, Barbara A., "Environmental and Farm Management Factors Associated with Tuberculosis on Cattle Farms in Northeastern Michigan" (2002). Michigan Bovine Tuberculosis Bibliography and Database. 54. https://digitalcommons.unl.edu/michbovinetb/54

This Article is brought to you for free and open access by the Wildlife Disease and Zoonotics at DigitalCommons@University of Nebraska - Lincoln. It has been accepted for inclusion in Michigan Bovine Tuberculosis Bibliography and Database by an authorized administrator of DigitalCommons@University of Nebraska Lincoln. 


\title{
Environmental and farm management factors associated with tuberculosis on cattle farms in northeastern Michigan
}

\author{
John B. Kaneene, DVM, MPH, PhD; Colleen S. Bruning-Fann, DVM, MS; Larry M. Granger, DVM; \\ RoseAnn Miller, BS; Barbara A. Porter-Spalding, DVM
}

\begin{abstract}
Objective-To identify major environmental and farm management factors associated with the occurrence of tuberculosis (TB) on cattle farms in northeastern Michigan.
\end{abstract}

Design-Case-control study.

Sample Population-17 cattle farms with infected cattle and 51 control farms.

Procedure-Each case farm (laboratory confirmed diagnosis of Mycobacterium bovis infection) was matched with 2 to 4 control farms (negative whole-herd test results within previous 12 months) on the basis of type of farm (dairy or beef) and location. Cattle farm data were collected from in-person interviews and mailed questionnaires. Wildlife TB data were gathered through state wildlife surveillance. Environmental data were gathered from a satellite image-based geographic information system. Multivariable conditional logistic regression for matched analysis was performed.

Results-Major factors associated with increased farm risk of TB were higher TB prevalence among wild deer and cattle farms in the area, herd size, and ponds or creeks in cattle housing areas. Factors associated with reduced farm risk of TB were greater amounts of natural open lands in the surrounding area and reducing deer access to cattle housing areas by housing cattle in barns, barnyards, or feedlots and use of electrified wire or barbed wire for livestock fencing.

Conclusions and Clinical Relevance-Results suggest that certain environmental and management factors may be associated with risk of TB on cattle farms. (J Am Vet Med Assoc 2002;221:837-842)

\footnotetext{
fter decades of effort by the livestock industry, Michigan was accredited by the USDA to be free from tuberculosis (TB) in 1979. However, Mycobacterium bovis infection was identified in free-ranging white-tailed deer (Odocoileus virginianus) during 1994, and subsequent wildlife surveillance during 1995 confirmed that TB was endemic in the wild deer population in northeastern

From the Population Medicine Center, College of Veterinary Medicine, Michigan State University, East Lansing, MI 48824 (Kaneene, Miller); USDA:APHIS:VS, 3001 Coolidge, Suite 125, East Lansing, MI 48823 (Bruning-Fann); the Michigan Department of Agriculture, 525 W Allegan, Lansing, MI 48933 (Granger); and the Department of Comparative Biomedical Sciences/Population Medicine, College of Veterinary Medicine, North Carolina State University, Raleigh, NC 27606 (Porter-Spalding).

Supported by the USDA-CSREES (Contract \#00-34427-8853), the Michigan Department of Natural Resources, the Michigan Department of Agriculture, and the Population Medicine Center, Michigan State University.

Address correspondence to Dr. Kaneene.
}

Michigan. ${ }^{1}$ Because of the potential for spread of this disease from wildlife to livestock and the serious consequences of TB for the livestock industry, intense surveillance of livestock operations was conducted in the area around where the first deer confirmed to have TB was located (designated the TB core area) and in the 5 surrounding counties in northeastern Michigan (Fig 1).

As a result of this increased surveillance, beef cattle with positive reactions to a comparative cervical skin test were identified, and subsequent necropsy, histologic examination, and mycobacterial culture confirmed that cattle were infected with $M$ bovis. Subsequent to this, 18 cattle farms were identified as having cattle with TB, and the state of Michigan lost its status as being free from TB in 2000.

To combat further spread of the disease, a quarantine zone was established around the 5 affected counties, incorporating a buffer zone that extended into 6 additional counties (Fig 1). Cattle movement into and out of the quarantine zone was heavily restricted, resulting in economic and emotional hardships for operators in this zone. In March 2000, more aggressive TB testing requirements were put into place, mandating annual caudal skin fold testing of all livestock in a 4-county area where the risk of TB was considered to be highest, and the quarantine was removed.

Genetic analysis of strains of $M$ bovis isolated from affected cattle has shown them to be identical to strains affecting white-tailed deer in Michigan, ${ }^{2,3}$ suggesting a common source of infection for cattle and wildlife. Because $M$ bovis is not native to free-ranging cervids, the disease in all likelihood spilled over from cattle at some time in the past. It is now believed that the wild deer population in northeastern Michigan has been infected with $M$ bovis for decades, possibly since the $1950 \mathrm{~s},{ }^{4}$ and that the prevalence of infection increased until it reached a detectable level in the 1990s. It is further thought that prevalence reached the point at which wildlife could serve as a source of $M$ bovis infection for livestock on farms in the area.

The fundamental question of why some cattle farms have been affected by TB when other farms in the same area have remained free from infection is still unanswered. Although all farms that have been identified to date as being affected by TB have been located in a single area of the state, these farms were not all located in the TB core area, where the prevalence of TB in wild deer was the highest. Affected farms included beef and dairy farms and encompassed a variety of herd and farm management practices. The purpose of the study reported here was to identify major environmental and farm management 


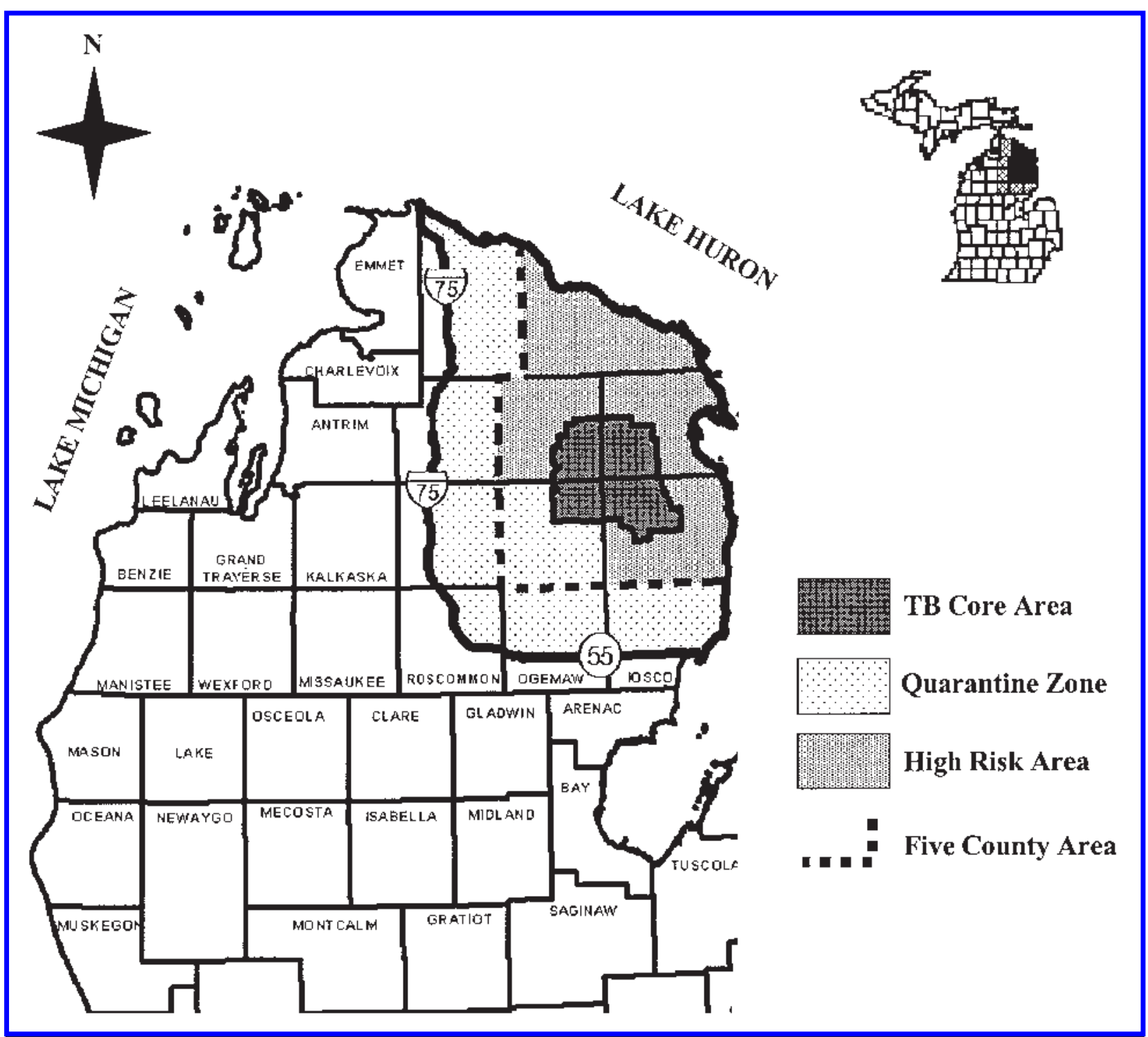

Figure 1-Map of the region of northeastern Michigan in which Mycobacterium bovis infection was identified in cattle and free-ranging white-tailed deer. The dark-shaded area (TB core area) represents the area where the first deer confirmed to have tuberculosis during 1994 was located. The light-shaded area (high risk area) represents the area where the risk of tuberculosis was considered to be the highest. The area enclosed by the dotted line ( 5 county area) represents the area where intense surveillance of livestock operations was conducted. The stippled area (quarantine zone) represents the area where cattle movement was restricted.

factors associated with the occurrence of TB on cattle farms in northeastern Michigan.

\section{Materials and Methods}

Study design-A retrospective matched case-control study design was used to identify specific environmental and farm management factors associated with the occurrence of TB on cattle farms in northeastern Michigan.

Selection of case and control farms-As of September 15, 2001, 18 farms in northeastern Michigan had been identified as having cattle infected with $M$ bovis. Of these farms, 17 had completed epidemiologic investigations and were included in the present study (case farms). The eighteenth farm was still under investigation at the time and was not included.

Two to 4 control farms matched to each case farm on the basis of type of farm (dairy or beef) and location (inside or outside the TB core area) were included in the study. Control farms were selected from all cattle farms located in the quarantine zone. Control farms were considered to be free from $\mathrm{TB}$ on the basis of results of cervical skin testing performed on the entire herd within the previous 12 months.

Data collection-Data on herd management practices of the case farms were collected via in-person interviews of farm managers at the time the herd was classified as positive for TB. Because of financial limitations, data on herd management practices of the control farms were collected with pretested mailed questionnaires. Types of data collected included type of housing facilities, information on cattle purchases, feeding and watering procedures, whether there were ponds or streams in the cattle pastures, feed storage facilities, and feed storage practices.

Data were also collected on free-ranging white-tailed deer in the quarantine zone. The location of each farm in the study was identified as the square mile $\left(2.59 \mathrm{~km}^{2}\right)$ townshiprange-section (TRS) block in which the majority of the farm 
was located. The apparent prevalence of bovine TB in deer was computed for each farm's TRS block and for the 8 blocks surrounding the farm's TRS block (ie, a $3 \times 3$ square of TRS blocks; $23.31 \mathrm{~km}^{2}$ ). This expanded area was used to account for deer movement, as deer in the area have been reported to have home ranges of approximately $12.95 \mathrm{~km}^{2}$. Including all deer within a $3 \times 3$ square of TRS blocks centered on the farm of interest should account for any deer that might come into contact with the farm. Data on TB-affected deer in the quarantine zone between 1996 and 1999 were obtained from the Michigan Department of Natural Resources and Michigan State University.

Data on environmental conditions were derived from Landsat program images $\left(30 \mathrm{~m}^{2}\right.$ resolution) developed into a geographic information system landscape-coverage database. Information on landscape coverage was available for 32 land use types, from which coverage of interest was selected. Landscape coverage was grouped into the following environmental condition categories: hardwood forests, coniferous forests, mixed (hardwood and conifer) forests, open areas and shrub lands (nonagricultural, nonresidential use), wetlands and swamps, agricultural use, open water (eg, ponds, lakes, and rivers), and all others (eg, industrial, mining, and urban or suburban use). Environmental conditions were then expressed as a percentage of the total acreage in the $3 \times 3$ square of TRS blocks centered on each farm.

Statistical analyses-To determine which risk factors were associated with odds of a farm acquiring $M$ bovis infection, the following steps were used. First, a list of risk factors ( $\mathrm{n}=25$ ) thought to potentially influence the odds of a farm acquiring $M$ bovis infection was generated. Second, univariable analyses were conducted by use of conditional logistic regression for matched analyses ${ }^{5}$ to identify factors for inclusion in multivariable analyses. Factors associated with odds of a farm acquiring $M$ bovis infection at a $P$ value $\leq 0.2$ were included in the multivariable logistic regression model. Variables that were considered to be potential confounders were forced into the model. These variables included prevalence of TB in cattle and deer around the farm, environmental conditions around the farm, and herd size.

In addition to risk factors describing specific management practices, 2 indices were developed to provide more generalized measures of practices that attract deer to livestock areas or restrict deer from livestock areas (Appendix). It was thought that although individual herd management practices themselves might not exert a significant influence on the odds of $\mathrm{TB}$, a combination of several factors (eg, storing hay outdoors without covers or bags and providing cattle hay in pasture areas where deer can gain access) might. Creating the 2 indices offered 2 advantages. First, this approach reduced the number of variables to be used in the multivariable analysis, by combining 5 closely related cattle feeding variables into a single variable (deer feed access index) and combining 4 closely related cattle housing variables into a single variable (deer exclusion index). Second, this approach eliminated the problem of multicollinearity among those variables.

The final multivariable statistical model was generated with a backward model building procedure. In brief, a full model was generated, and possible interactions and confounding were assessed and corrected during the model development process. ${ }^{6}$ The full model included prevalence of TB in cattle and deer around the farm, environmental conditions around the farm, herd size, the deer exclusion index, the deer feed access index, and other risk factors not included in the indices. Excluding variables included in the 2 indices, interaction terms that were tested included those for the interaction between fence line contact with other livestock and the presence of ponds or creeks in cattle housing areas, the interaction between fence line contact with other livestock and the feeding of unbaled hay to cattle, and the interaction between herd size and the feeding of unbaled hay to cattle. Odds ratios (OR) with 95\% confidence intervals were computed for parameter estimates. With the exception of the potential confounders forced into the model, each risk factor was tested by examining the effects of removal of that factor from the model. If removal of the risk factor resulted in a change in the OR of the remaining variables of $>10 \%$, the risk factor and its interaction terms were retained in the model.

\section{Results}

Seventeen case farms and 51 control farms were used in the study. Although the goal of the study was to enroll 4 control farms for each case farm, there were an insufficient number of control farms in the TB core area to meet this goal. Consequently, 4 case herds were matched with 4 control herds, 9 case herds were matched with 3 control herds, and 4 case herds were matched with 2 control herds.

Fifteen (88\%) case herds were beef farms and 2 (12\%) were dairy farms; 11 (65\%) were located in the TB core area. Forty-three (84\%) control herds were beef farms and 8 (16\%) were dairy farms; 31 (61\%) were located in the TB core area. Herd size ranged from $<25$ to $>100$ cattle. Three $(18 \%)$ case farms and 17 (33\%) control farms had $<25$ cattle, 4 (24\%) case farms and 18 (35\%) control farms had 25 to 49 cattle, $4(24 \%)$ case farms and 7 (14\%) control farms had 50 to 99 cattle, and 6 (35\%) case farms and 9 (18\%) control farms had $>100$ cattle.

Approximately $50 \%$ of the land surrounding farms in the study was forested, with hardwood forests making up most of these forests (Table 1). Agricultural

Table 1-Percentage of the surrounding landscape covered by various environmental conditions for cattle farms in northeastern Michigan with cattle infected with Mycobacterium bovis (case farms; $n=17$ ) and for uninfected control farms (51)

\begin{tabular}{|lrrrrrr|}
\hline & \multicolumn{3}{c}{ Percentage of landscape coverage } & \\
\cline { 2 - 3 } Environmental & \multicolumn{2}{c}{ Case farms } & & \multicolumn{2}{c|}{ Control farms } & \\
\cline { 2 - 3 } condition & Mean & SD & & Mean & SD & P value \\
\hline All forests & 54.7 & 15.2 & & 52.5 & 17.6 & 0.635 \\
Mixed forests & 20.2 & 11.3 & & 20.9 & 13.1 & 0.994 \\
Hardwood forests & 31.0 & 21.2 & & 26.7 & 19.4 & 0.492 \\
Coniferous forests & 3.7 & 3.0 & & 4.8 & 4.8 & 0.676 \\
Open land & 8.6 & 3.7 & & 12.5 & 4.7 & 0.003 \\
Wetlands and swamps & 2.9 & 6.0 & & 1.4 & 1.1 & 0.432 \\
Agricultural use & 22.1 & 9.1 & 23.6 & 11.5 & 0.676 \\
\hline
\end{tabular}

Table 2-Environmental conditions for cattle farms in northeastern Michigan with cattle infected with $M$ bovis (case farms; $n=$ 17) and for uninfected control farms (51)

\begin{tabular}{|c|c|c|c|c|c|}
\hline \multirow[b]{2}{*}{ Factor } & \multicolumn{2}{|c|}{ Case farms } & \multicolumn{2}{|c|}{ Control farms } & \multirow[b]{2}{*}{$P$ value } \\
\hline & Mean & SD & Mean & SD & \\
\hline \multicolumn{6}{|l|}{ Harvested deer } \\
\hline Percentage male & 47.3 & 8.9 & 51.1 & 10.0 & 0.181 \\
\hline Age (y) & 2.6 & 0.3 & 2.6 & 0.3 & 0.697 \\
\hline $\begin{array}{l}\text { Prevalence of TB } \\
\text { (per } 100 \text { deer) }\end{array}$ & 2.3 & 2.4 & 1.2 & 1.7 & 0.027 \\
\hline \multicolumn{6}{|c|}{$\begin{array}{l}\text { Number of TB-affected farms } \\
\ln 3 \times 3 \text { square of }\end{array}$} \\
\hline TRS blocks & 1.5 & 1.7 & 0.5 & 0.9 & 0.017 \\
\hline In same TRS block & 0.6 & 0.8 & 0.2 & 0.4 & 0.016 \\
\hline
\end{tabular}


Table 3-Results of univariable analysis of potential risk factors for $M$ bovis infection among cattle farms in northeastern Michigan

\begin{tabular}{|c|c|c|c|}
\hline Factor & $P$ value & Odds ratio & $95 \% \mathrm{CI}$ \\
\hline Prevalence of TB in deer (per 100 deer) & 0.060 & 1.30 & $0.99-1.70$ \\
\hline No. of TB-affected farms in same TRS block & 0.039 & 2.99 & $1.06-8.45$ \\
\hline No. of TB-affected farms in $3 \times 3$ square of TRS blocks & 0.007 & 0.78 & $0.65-0.94$ \\
\hline Herd size & 0.024 & 1.74 & $1.08-2.82$ \\
\hline Purchase $>50 \%$ of herd each year & 0.175 & 2.38 & $0.68-8.32$ \\
\hline Fence-line contact with other livestock & 0.030 & 4.32 & $1.15-16.20$ \\
\hline Cattle spend some time in barn, feedlot, or barnyard & 0.007 & 0.13 & $0.03-0.58$ \\
\hline Barbed wire or electrified wire fencing used & 0.004 & 0.09 & $0.02-0.47$ \\
\hline Cattle watered outdoors & 0.067 & 1.99 & $0.95-4.17$ \\
\hline Ponds or creeks in cattle areas & 0.009 & 5.66 & $1.55-20.63$ \\
\hline Hay fed on the ground, rather than in feeder & 0.065 & 3.11 & $0.93-10.40$ \\
\hline Loose hay fed, rather than baled hay & 0.010 & 5.09 & $1.48-17.48$ \\
\hline Small-quantity hay bales used & 0.005 & 0.09 & $0.02-0.49$ \\
\hline Hay stored outdoors & 0.026 & 1.90 & $1.08-3.33$ \\
\hline Large-quantity hay bales left in fields or fence rows & 0.020 & 4.70 & $1.28-17.26$ \\
\hline Hay protected & 0.005 & 0.10 & $0.02-0.49$ \\
\hline Deer exclusion index* & 0.001 & 0.31 & $0.16-0.58$ \\
\hline Deer access to feed index* & 0.003 & 2.26 & $1.33-3.86$ \\
\hline
\end{tabular}

\section{Discussion}

The presence of a known wildlife reservoir of $\mathrm{TB}$ in northeastern Michigan presents challenges for cattle producers attempting to control this disease in their livestock. An owner may be able to alter his or her farm management practices to reduce the risk of TB among cattle on the farm, but it is unlikely that he or she will be able to exert any substantial control on extrinsic environmental and wildlife factors. Consequently, it is important to recognize the effects of extrinsic environmental and wildlife factors on TB risk. The model devel-

Table 4-Results of multivariable conditional logistic regression of the risk of $M$ bovis infection among cattle farms in northeastern Michigan

\begin{tabular}{|lccc|}
\hline Factor & $\boldsymbol{P}$ value & Odds ratio & $\mathbf{9 5 \%} \mathbf{~ c ~}$ \\
\hline $\begin{array}{l}\text { Prevalence of TB in deer (per 100 deer) } \\
\text { No. of TB-affected farms in same }\end{array}$ & 0.430 & 1.18 & $0.78-1.79$ \\
$\quad$ TRS block & 0.060 & 5.03 & $0.93-27.32$ \\
$\begin{array}{l}\text { Percentage of open land in 3 X3 square } \\
\quad \text { of TRS blocks }\end{array}$ & 0.047 & 0.77 & $0.60-0.99$ \\
$\quad$ Herd size & 0.634 & 1.21 & $0.46-2.61$ \\
Deer exclusion index & 0.002 & 0.29 & $0.13-0.64$ \\
Ponds or creeks in cattle areas & 0.057 & 6.94 & $0.94-51.07$ \\
\hline
\end{tabular}

land was also common, whereas swamps and coniferous forests were uncommon. Case farms had a significantly lower percentage of open land around their farms than did control farms.

Age and sex of wild deer harvested around study farms were not significantly different between case and control farms (Table 2). However, the apparent prevalence of TB in harvested deer was significantly higher in areas around case farms than in areas around control farms, and the number of TB-affected farms around the farm of interest was significantly higher for case farms than for control farms, both within the TRS block in which the farm of interest was located and within the $3 \times 3$ square of TRS blocks centered on the farm.

Eighteen factors were found in univariable analyses to be associated with odds of a farm acquiring $M$ bovis infection at a $P$ value $\leq 0.2$ and were included in the multivariable logistic regression analysis (Table 3). Factors retained in the multivariable model that were associated with an increased risk of TB included prevalence of TB in wild deer around the farm, number of affected farms in the same TRS block as the farm of interest, and the presence of ponds or creeks in cattle housing areas (Table 4). Factors retained in the multivariable model that were associated with a reduced risk of TB were percentage of surrounding land classified as open land and deer exclusion index. oped in the present study was designed to account for the effects of environmental conditions and local TB prevalence on a farm's risk of developing $\mathrm{TB}$ and to assess farm management risk factors.

Results of the present study suggested that the local prevalence of TB, both in wild deer and on neighboring cattle farms, was an important risk factor for TB. An increase in prevalence of $\mathrm{TB}$ in wildlife provides an increased potential for exposure of cattle to infected deer, either through direct contact with infected deer or through contamination of local environments by deer. A similar effect was identified in a study ${ }^{7}$ in Ireland, in which the presence of a wildlife host for $M$ bovis (the European badger [Meles meles]) was associated with an increased risk of a cattle farm developing TB.

Proximity to other TB-affected cattle farms, particularly contiguous farms, has been associated with an increased risk of TB in some previous studies. ${ }^{7,8}$ In the present study, a larger number of TB-affected farms in the same TRS block as the farm of interest could have increased the potential for exposure to TB-infected cattle. Practices identified by investigators on some case farms that could have increased exposure to infected cattle were direct physical contact between herds over fences, sharing of pastures or facilities, sharing of bulls, and trading of cattle between farms. Additionally, a contiguous TB-affected herd may not itself be a source of infection for a farm but could indicate a common source of infection for both farms.

Associations were seen between farm TB status and specific environmental conditions in the present study. In particular, a greater percentage of natural open land in the surrounding area was strongly associated with a decreased risk of TB. Open meadows are not preferred deer bedding areas, and although deer may pass through these areas, they typically do not stay there for extended periods. Percentage of surrounding area that was hardwood forest and percentage that was wetlands or swamps were not significantly associated with risk of TB in the present study. Forested areas and wetlands provide good 
cover and natural feed for deer, and deer might be expected to spend substantial amounts of time in these areas. Because the most efficient means of transmitting TB between animals is close contact, ${ }^{9}$ areas where deer spend large amounts of time in close proximity with each other would likely be areas where TB is spread more efficiently through the wild deer population.

The deer exclusion index was found to be associated with a reduced risk of TB in the present study. This index included whether cattle were housed in a barn, feedlot, or barnyard and whether barbed wire or electrified wire was used for livestock fencing. Higher cattle density and higher levels of cattle and human activity in these area would make these locations less likely to attract deer and, consequently, reduce the likelihood of contact with infected deer. Any food or water provided to cattle in this type of housing is typically consumed more completely and quickly than feed left for cattle in pastures. Thus, this type of housing would be expected to reduce opportunities for feed to attract deer and become contaminated by infected animals. Our findings, therefore, suggest that herds managed for more intensive production are less likely to develop TB under current conditions in northeastern Michigan. Interestingly, an earlier study ${ }^{10}$ of dairy herds and bovine TB in Ireland found that more intensively managed herds were at higher risk for recurring outbreaks of TB. However, that study was limited to dairy farms, whereas most of the TB-affected cattle farms in Michigan have been beef cattle farms. Dairy cattle management is not equivalent to beef cattle management, and differences in management practices may explain the difference in effects seen with intensive production conditions. Finally, it is likely that differences in the behavioral ecology of the 2 wildlife reservoirs (European badgers in Ireland and white-tailed deer in Michigan) would result in differences in the influence of management practices on the risk of herd TB exposure and infection.

Another component of the deer exclusion index, type of farm fencing, is considered to be an important component of herd biosecurity. The reduced risk of TB with use of barbed wire or electrified wire fencing may be attributable to its effectiveness in keeping cattle in and keeping deer out of cattle housing areas. Also, although electrified fencing was common, many farms used electrified wire fencing in combination with barbed wire and other fencing, and some used a combination of woven wire and barbed wire fencing. These combinations of fencing may be more effective at keeping deer out of livestock housing areas and keeping cattle confined on the farm. Finally, the use of these types of fencing may be associated with the quality of livestock housing and management, which may be more directly associated with a decrease in risk of TB. Fence height was considered to be an important factor for consideration but could not be analyzed in the present study, as all farms reported having fencing of similar heights (between 1 and $1.5 \mathrm{~m}$ ). Importantly, fencing $<3 \mathrm{~m}$ in height is considered inadequate for excluding deer.

Strong associations were seen between risk of TB and the presence of ponds or creeks in cattle areas in the present study. Types and relative density of vegetation growing around these natural water sources are often quite different from types and relative density of vegetation growing on the rest of an open pasture, as the additional moisture allows plants to grow and remain green during periods of low rainfall, and the physical terrain around these areas (eg, unstable or steep creek banks or pond shores) may make it difficult for cattle to effectively graze. The combined presence of water and vegetation may attract deer to these locations, which would increase the likelihood of infected deer contaminating vegetation around the water source with $M$ bovis. The higher levels of moisture around ponds and creeks and the greater amounts of shade can provide conditions associated with environmental survival of $M$ bovis. ${ }^{11-13}$ Finally, cattle access to surface water may be an indirect measure of other farm management practices. Cattle may have unintentional access to these water sources because of poor fencing and biosecurity, and farms that are unable to provide adequate quantities of water in tanks and troughs may have to rely on these natural water sources. Cattle on pastures with surface water sources may not be monitored as closely as those on pastures with artificial water sources, where monitoring would be needed to ensure that adequate water was available for the cattle. A casecontrol study ${ }^{10}$ of dairy farms in Ireland found no association between exposure to surface water and herd TB status, but as mentioned earlier, differences in the type of cattle operation (dairy farms in Ireland vs primarily beef farms in Michigan) and wildlife reservoir (badgers in Ireland vs white-tailed deer in Michigan) may account for this discrepancy in findings.

Several potential risk factors found to be associated with risk of TB in univariable analyses were not maintained in the final multivariable model but provided interesting observations that need further study. In general, farm biosecurity factors that increased the likelihood of cattle coming in contact with potentially infected animals increased the risk of $\mathrm{TB}$, whereas biosecurity practices that reduced contact decreased herd risk. Fence-line contact with other livestock and purchasing large numbers of cattle increased the risk of TB for the farm. Providing water to cattle outdoors was associated with an increased risk, probably because this would attract infected wildlife. ${ }^{14}$

Proper feed storage, particularly for hay, was found to decrease the farm risk for TB. Protecting hay through bagging, wrapping, or indoor storage reduces access to hay by wildlife, which reduces opportunities for feed contamination. Additionally, making all hay inaccessible to deer removes a factor that might attract deer onto the farm. Finally, protecting hay may be a proxy measure for other cattle herd management practices that actually protect herds from development of TB. Storing largequantity hay bales in fields or on pasture fence lines was associated with an increased risk of TB, possibly because of contamination by wild deer. Providing hay on the ground, rather than in feeders, and providing loose hay, rather than hay in bales, were also associated with an increased risk of TB. A common method observed for feeding large-quantity hay bales in pastures was unrolling a large $(544 \mathrm{~kg}[1,200 \mathrm{lb}])$ round bale, which would allow easier access for cattle to the hay but also provide easier access for deer and attract more deer to the pasture. If small-quantity (20 kg [44 lb]) square 
bales are provided for feeding, both the amount of hay and the time the hay is available for contamination by deer are reduced, and the smaller size of these bales makes them easier to handle and store indoors, compared with large bales.

This study provides useful information, but further work needs to be done. The number of case farms in this study was low, but the number of infected farms that have been identified is slowly increasing. Adding new case farms and matching control farms as they are identified will improve the power of this study. It would be of interest to compare farms in this study with farms in other parts of the state of Michigan to address the question as to why only this area has been affected by TB. Finally, in-depth analyses of farm biosecurity, cattle feeding practices, and feed storage methods should be conducted with the specific goal of examining how minimizing wildlife contact with the livestock environment reduces the chances for transfer of $M$ bovis infection from infected wildlife to and from livestock.

\section{Appendix}

Indices of generalized measures of practices that attract deer to livestock areas or restrict deer from livestock areas

\begin{tabular}{|c|c|c|}
\hline \multirow[b]{2}{*}{ Score } & \multirow[b]{2}{*}{ Factors } & \multirow[t]{2}{*}{ Deer exclusion index } \\
\hline & & \\
\hline 1 & \multicolumn{2}{|c|}{ Cattle housed in barn feedlot or barnvard } \\
\hline 1 & \multicolumn{2}{|c|}{ Cattle spend $>50 \%$ of time in barn, feedlot, or barnyard } \\
\hline 1 & \multicolumn{2}{|c|}{ Barbed wire used for livestock fencing } \\
\hline \multirow[t]{2}{*}{1} & Electrifie & used for livestock fencing \\
\hline & & Deer feed access index \\
\hline Score & \multicolumn{2}{|l|}{ Factors } \\
\hline 1 & \multicolumn{2}{|c|}{ Cattle fed indoors and outdoors } \\
\hline 2 & \multirow{2}{*}{\multicolumn{2}{|c|}{ Cattle fed outdoors only }} \\
\hline 1 & \multirow{2}{*}{\multicolumn{2}{|c|}{ Hay not provided in a feeder }} \\
\hline 1 & & \\
\hline 1 & \multicolumn{2}{|c|}{$\begin{array}{l}\text { Hay stored outdoors and unprotected } \\
\text { Round bale hay left in field or along fence line }\end{array}$} \\
\hline
\end{tabular}

\section{References}

1. Schmitt SM, Fitzgerald SD, Cooley TM, et al. Bovine tuberculosis in free-ranging white-tailed deer in from Michigan. $\underline{\text { Wildlife }}$ Dis 1997;33:749-758.

2. Palmer MV, Whipple DL, Payeur JB, et al. Naturally occurring tuberculosis in white-tailed deer. I Am Vet Med Assoc 2000;216: 1921-1924.

3. Kaneene JB, Vanderklok M, Bruning-Fann CS, et al. The prevalence of Mycobacterium bovis in privately-owned cervid ranches in Michigan. IAm Vet Med Assoc 2002;220:656-660.

4. Assessing the risks associated with $M$ bovis in Michigan freeranging white-tailed deer. CADIA technical report No. 01-96. Fort Collins, Colo: USDA:APHIS:VS Centers for Epidemiology and Animal Health, 1997;B1-B8.

5. The PHREG procedure. In: SAS/STAT user's guide, version 8. Cary, NC: SAS Institute Inc, 1999;2569-2658.

6. Kleinbaum DG. Logistic regression: a self-learning text. New York: Springer-Verlag Inc, 1994;191-221.

7. Griffin JM, Martin SW, Thorburn MA, et al. A case-control study on the association of selected risk factors with the occurrence of bovine tuberculosis in the Republic of Ireland. Prev Vet Med 1996; 27:75-87.

8. Denny GO, Wilesmith JW. Bovine tuberculosis in Northern Ireland: a case-control study of herd risk factors. Vet Rec 1999; 144:305-310. 48:578.

9. Francis J. Route of infection in tuberculosis. Aust Vet I 1972;

10. Griffin JM, Hahesy T, Lynch K, et al. The association of cattle husbandry practices, environmental factors and farmer characteristics with the occurrence of chronic bovine tuberculosis in dairy herds in the Republic of Ireland. Prev Vet Med 1993;17: $145-160$.

11. Wray C. Survival and spread of pathogenic bacteria of veterinary importance within the environment. Vet Bull 1975;45: 543-550.

12. Jackson R, de Lisle GW, Morris RS. A study of the environmental survival of Mycobacterium bovis on a farm in New Zealand. N Z Vet I 1995;43:346-352.

13. Tanner M, Michel AL. Investigation of the viability of $M$ bovis under different environmental conditions in the Kruger National Park. Onderstepoort I Vet Res 1999;66:185-190.

14. Zoonotic tuberculosis (Mycobacterium bovis)—memorandum from a WHO meeting (with the participation of the FAO). Bull World Health Organ 1994;72:851-857. 